\title{
Community Participation in Cholangiocarcinoma Prevention in Ubon Ratchathani, Thailand: Relations with Age and Health Behavior
}

\author{
Nopparat Songserm ${ }^{1 *}$, Onanong Bureelerd ${ }^{1}$, Sumaporn Thongprung ${ }^{1}$, \\ Somkiattiyos Woradet ${ }^{2}$, Supannee Promthet ${ }^{3}$
}

\begin{abstract}
A high prevalence of Opisthorchis viverrini infection is usually found in wetland geographical areas of Thailand where people have traditional behavior of eating uncooked freshwater fish dishes which results in cholangiocarcinoma (CCA) development. There were several approaches for reducing opisthorchiasis-linked CCA, but the prevalence remains high. To develop community participation as a suitable model for CCA prevention is, firstly, to know what factors are related. We therefore aimed to investigate factors associated with the community participation in CCA prevention among rural residents in wetland areas of Ubon Ratchathani, Thailand. This was a cross-sectional analytic study. All participants were 30-69 years of age, and only one member per house was invited to participate. A total of 906 participants were interviewed and asked to complete questionnaires. Independent variables were socio-demographic parameters, knowledge, health belief and behavior to prevent CCA. The dependent variable was community participation for CCA prevention. Descriptive statistics were computed as number, percentage, mean and standard deviation. Associations were assessed using logistic regression analysis with a $P$-value $<\mathbf{0 . 0 5}$ considered statistically significant. Of all the participants, more than $60 \%$ had regularly participated in activities to prevent CCA following health officials advice. Age and health behavior to prevent CCA were factors associated with community participation for $\mathrm{CCA}(\mathrm{p}<\mathbf{0 . 0 0 1})$. Both factors will be taken into consideration for community participation approaches for CCA prevention through participatory action research $(\mathbf{P A R})$ in future studies.
\end{abstract}

Keywords: Community participation - cholangiocarcinoma - prevention - Thailand

Asian Pac J Cancer Prev, 16 (16), 7375-7379

\section{Introduction}

The incidence of cholangiocarcinoma (CCA) in Northeast Thailand accounts for about $60 \%$ to $90 \%$ (Kamsa-ard et al., 2011; Khuhaprema et al., 2013), which differ from about 15\% worldwide (Parkin et al., 1993). According to the last report - Cancer in Thailand, Vol. VII, 2007-2009 - the incidence (age-standardized incidence rate, ASR) of liver and bile duct cancers in Thailand is 40.3 per 100,000 in men and 16.6 per 100,000 in women. The ASRs per 100,000 in the Northeast region of Thailand are 67.1 in men and 30.9 in women. Also, the ASRs in Ubon Ratchathani in men and women are 67.4 and 29.6 per 100,000 , respectively. Similar to other northeastern provinces, Ubon Ratchathani has reported CCA cases as the great majority (71\% in men and $75 \%$ in women) (Khuhaprema et al., 2013).

Ubon Ratchathani is one of the northeastern provinces in Thailand which has the Thai-Lao-Cambodia border areas. Most areas are wetland surrounded with Chi River, Se Bai River, Mun River and Mekong River. Based on the data from the geographic information system, the wetland areas show high prevalence rate of Opisthorchis viverrini (O. viverrini) infection than other areas (Wattanayingcharoenchai et al., 2011). From the survey in all of 19 northeastern provinces of Thailand in 2009, it was reported that the prevalence of $O$. viverrini infection in Ubon Ratchathani was $20.2 \%$ from $16.6 \%$ overall of the Northeast, which is still high prevalent (Sithithaworn et al., 2012). Rural residents in this area have traditional behaviors of eating uncooked freshwater fish dishes for several decades (Vatanasapt et al., 1990; Sripa et al., 2007; Grundy-Warr et al., 2012). This consumption behavior is a vehicle of $O$. viverrini infection resulting in progression to CCA (Songserm et al., 2012; Manwong et al., 2013).

Opisthorchiasis-linked CCA is known to be a specific public health problem for a long time in the Greater Mekong Sub-regional Countries, especially in Thailand

${ }^{1}$ Department of Community Health, Faculty of Public Health, Ubon Ratchathani Rajabhat University, Ubon Ratchathani, ${ }^{2}$ Department of Public Health, Faculty of Health and Sports Science, Thaksin University, Phatthalung, ${ }^{3}$ Department of Epidemiology, Faculty of Public Health, Khon Kaen University, Thailand *For correspondence: nopparat.s@ubru.ac.th 
(Parkin et al., 1991; Sriamporn et al., 2004; Sripa et al., 2007; Sithithaworn et al., 2012; Thaewnongiew et al., 2014). There were several methods for solving this problem in Thailand from the past until now (Jongsuksuntigul and Imsomboon, 1998; Jongsuksuntigul and Imsomboon, 2003; Wongba et al., 2011; Duangsong et al., 2013) but it seems not effective outcome, resulting in prevalence of opisthorchiasis and incidence of high CCA today. Community participation may be used as alternative way in studying behavior modification for CCA prevention. However, development of the community participation as a suitable model is needed to firstly know what factors are related to them. Therefore, this study aimed to investigate factors associated with the community participation for CCA prevention among rural people residing near wetland areas in Ubon Ratchathani, Thailand.

\section{Materials and Methods}

\section{Study design}

A community-based cross-sectional analytic study was conducted in a sub-district in Muang District of Ubon Ratchathani, Thailand. The study period was between July and August, 2014. This study site was near wetland areas surrounded with the Chi, Se Bai and Mun river basins, of which the topography looks like an island. Participants aging 30 to 69 were randomly recruited. Only one member per house was invited to participate. Following informed consent, a total of 906 participants were interviewed by trained interviewers and asked to complete the questionnaires. This research was approved by the Ethics Committee for Human Research of Ubon Ratchathani Provincial Public Health Office.

\section{Data collection}

Information was collected using a structuredquestionnaire. The questionnaire was divided into six parts. The first part was related to socio-demographic variables of the participants such as sex, age, occupation, education, household income per year and marital status. The second part was related to risk factors for CCA, comprising four major factors (smoking, alcohol drinking, history of liver fluke infection and praziquantel use, and dietary consumption). The third part was the section of knowledge on opisthorchiasis and CCA (10 items). A correct answer scored " 1 " while an incorrect answer scored " 0 ". Mean knowledge score was analyzed by totaling the number of correct answer divided by the total number of the items ( 10 items) and then classified by the mean into two categories, $\leq 7$ scores as low and $>7$ as high level. The fourth part was the section of health belief on opisthorchiasis and CCA, which includes four major subscales; perceived susceptibility (5 items), perceived seriousness ( 5 items), perceived benefits ( 5 items) and perceived barriers ( 5 items). Each item of 3-point scale was ranked from "disagree," "not sure" and "agree." A mean score for each subscale was used to classify its perception level ( $\leq$ mean as low and $>$ mean as high level). The fifth part was the section of preventing behavior for CCA (10 items). Each item of 3-point scale was ranked from "never," "sometimes" and "regular" practices. Mean behavior score was analyzed as same as the knowledge score ( $\leq 22$ scores as low and $>22$ as high level). The last part was the section of community participation for CCA prevention (10 items). Each item of 3-point scale was ranked from "never," "sometimes" and "regular" participates. Mean participate score was analyzed as same as the knowledge and the behavior scores ( $\leq 18.11$ scores as low and $>18.11$ as high level).

Content validity of the questionnaire was evaluated by five experts. The overall item-objective congruence (IOC) for content validity was 0.86 . The reliability test indicated that overall subscales had a good level of internal consistency (Cronbach's alpha coefficient, $\alpha \geq 0.72$ ). The knowledge on opisthorchiasis and CCA had $\alpha=0.72$.

Table 1. General Characteristics of Rural People Residing Near Wetland Areas in Ubon Ratchathani, Thailand $(n=906)$

\begin{tabular}{|c|c|c|}
\hline$\overline{\text { Variables }}$ & Number & $\%$ \\
\hline \multicolumn{3}{|l|}{$\overline{\operatorname{Sex}}$} \\
\hline Male & 329 & 36.31 \\
\hline Female & 577 & 63.69 \\
\hline \multicolumn{3}{|l|}{ Age (years) } \\
\hline$\leq 44$ & 240 & 26.49 \\
\hline $45-59$ & 434 & 47.90 \\
\hline$\geq 60$ & 232 & 25.61 \\
\hline Mean \pm SD & $51.39 \pm 10.29$ & \\
\hline Median (min: max) & $52(30: 69)$ & \\
\hline \multicolumn{3}{|l|}{ Occupation } \\
\hline Farmer/Laborer & 807 & 89.07 \\
\hline Commercial/Trading & 49 & 5.41 \\
\hline Government officer & 50 & 5.52 \\
\hline \multicolumn{3}{|l|}{ Education level } \\
\hline Primary school & 684 & 75.50 \\
\hline Secondary school & 180 & 19.87 \\
\hline Bachelor degree or higher & 42 & 4.63 \\
\hline \multicolumn{3}{|l|}{ Marital status } \\
\hline Single & 85 & 9.38 \\
\hline Married & 715 & 78.92 \\
\hline Divorced & 75 & 8.28 \\
\hline Widowed & 31 & 3.42 \\
\hline \multicolumn{3}{|c|}{ Household income per year (Baht) } \\
\hline$\leq 10,000$ & 192 & 21.19 \\
\hline $10,001-15,000$ & 151 & 16.67 \\
\hline$>15,000$ & 563 & 62.14 \\
\hline \multicolumn{3}{|c|}{ Knowledge on opisthorchiasis and CCA } \\
\hline Low ( $\leq 7$ scores $)$ & 560 & 61.81 \\
\hline $\operatorname{High}(>7$ scores $)$ & 346 & 38.19 \\
\hline \multicolumn{3}{|l|}{ Perceived susceptibility } \\
\hline Low ( $\leq 11.72$ scores $)$ & 431 & 47.57 \\
\hline High (>11.72 scores) & 475 & 52.43 \\
\hline \multicolumn{3}{|l|}{ Perceived seriousness } \\
\hline Low $(\leq 11.93$ scores $)$ & 283 & 31.24 \\
\hline High (>11.93 scores) & 623 & 68.76 \\
\hline \multicolumn{3}{|l|}{ Perceived benefits } \\
\hline Low $(\leq 12.72$ scores $)$ & 238 & 26.27 \\
\hline High (>12.72 scores) & 668 & 73.73 \\
\hline \multicolumn{3}{|l|}{ Perceived barriers } \\
\hline Low ( $\leq 12.13$ scores $)$ & 421 & 46.47 \\
\hline High (>12.13 scores) & 485 & 53.53 \\
\hline \multicolumn{3}{|c|}{ Preventing behavior for CCA prevention and control } \\
\hline Low $(\leq 22$ scores $)$ & 484 & 53.42 \\
\hline High (>22 scores) & 422 & 46.58 \\
\hline
\end{tabular}


Table 2. Community Participation in Cholangiocarcinoma Prevention among Rural People Residing Near Wetland Areas in Ubon Ratchathani, Thailand

\begin{tabular}{|c|c|c|c|c|c|c|c|c|}
\hline \multirow[t]{3}{*}{ Issues } & \multicolumn{6}{|c|}{ Community participation } & \multirow[b]{3}{*}{ Mean } & \multirow[b]{3}{*}{ SD } \\
\hline & \multicolumn{2}{|c|}{ Never } & \multicolumn{2}{|c|}{ Sometimes } & \multicolumn{2}{|c|}{ Regular } & & \\
\hline & Number & $\%$ & Number & $\%$ & Number & $\%$ & & \\
\hline \multicolumn{9}{|c|}{ Have you ever participated in any activities arranged by the communities or health promoting hospital? } \\
\hline & 247 & 27.26 & 369 & 40.73 & 290 & 32.01 & 2.05 & 0.77 \\
\hline \multicolumn{9}{|c|}{ Have you ever expressed your opinion in each meeting? } \\
\hline & 480 & 52.98 & 313 & 34.55 & 113 & 12.47 & 1.59 & 0.70 \\
\hline \multicolumn{9}{|c|}{ Have you ever cooperated with health officials in searching for the problem of cholangiocarcinoma? } \\
\hline & 714 & 78.81 & 137 & 15.12 & 55 & 6.07 & 1.27 & 0.57 \\
\hline \multicolumn{9}{|c|}{ Have you ever cooperated with health officials in analyzing the problem of cholangiocarcinoma? } \\
\hline & 748 & 82.56 & 116 & 12.80 & 42 & 4.64 & 1.22 & 0.51 \\
\hline \multicolumn{9}{|c|}{ Have you ever cooperated with health officials in planning to solve the problem of cholangiocarcinoma? } \\
\hline & 749 & 82.67 & 118 & 13.02 & 39 & 4.31 & 1.22 & 0.51 \\
\hline \multicolumn{9}{|c|}{ Have you ever cooperated with health officials in doing the activities to solve the problem of cholangiocarcinoma? } \\
\hline & 684 & 75.50 & 149 & 16.45 & 73 & 8.05 & 1.33 & 0.62 \\
\hline \multicolumn{9}{|c|}{ Have you ever eaten cooked freshwater-fish dishes in order to prevent from cholangiocarcinoma according to the health official } \\
\hline advice? & 81 & 8.94 & 272 & 30.02 & 553 & 61.04 & 2.52 & 0.65 \\
\hline \multicolumn{9}{|c|}{ Have you ever participated in activities preventing and controlling cholangiocarcinoma according to the health official's advice } \\
\hline & 64 & 7.06 & 189 & 20.86 & 653 & 72.08 & 2.65 & 0.61 \\
\hline \multicolumn{9}{|c|}{ Have you always taken the feces test for liver fluke eggs every time it was required? } \\
\hline & 148 & 16.34 & 210 & 23.18 & 548 & 60.48 & 2.44 & 0.76 \\
\hline \multicolumn{9}{|c|}{$\begin{array}{l}\text { Have you ever participated in activities that helped establish the health funds such as pay for liver fluke testing or pay for opisthorchias } \\
\text { treatment or donate fund for opisthorchiasis prevention and control? }\end{array}$} \\
\hline & 440 & 48.57 & 188 & 20.75 & 278 & 30.68 & 1.82 & 0.87 \\
\hline
\end{tabular}

The overall perceptions had $\alpha=0.76$, which is divided as susceptibility ( $\alpha=0.74)$, seriousness $(\alpha=0.77)$, benefits $(\alpha=0.80)$ and barriers $(\alpha=0.73)$. The CCA preventing behavior had $\alpha=0.73$. The community participation for CCA prevention had $\alpha=0.80$.

\section{Statistical analysis}

Independent variables were the socio-demographic variables, the knowledge on opisthorchiasis and CCA, the health belief on opisthorchiasis and CCA, and the preventing behavior for CCA. Dependent variable was the community participation for CCA prevention. Descriptive statistics were computed as number, percentage, mean and standard deviation. Inferential statistics were assessed by using a logistic regression analysis. A P-value $<0.05$ was considered statistically significant.

\section{Results}

The general characteristics of the 906 participants are shown in Table $1.36 .31 \%$ was male and $63.69 \%$ was female. The mean age was $51.39 \pm 10.29$ years, ranging from 30 to 69 . More than $75 \%$ of the participants were married, were farmer/laborer and had completed primary school education. Most participants' household income per year was more than 15,000 Baht $(62.14 \%)$. Of all the participants, most of them $(61.81 \%)$ were the participants with knowledge on opisthorchiasis and CCA in low level. In addition to such knowledge, the CCA preventing behavior of almost participants was in low level (53.42\%). With respect to the health belief analysis, all of 4 subscales were in the high perceptions (more than 50\%).

Table 2 shows the community participation for CCA prevention among the participants. Most of them had regularly participated in activities to prevent CCA as the health official's advice. For example, they were allowed of eating the cooked freshwater fish dishes or allowed of testing liver fluke eggs from their feces. On the contrary, there were some issues that most participants had never participated; for example, they had never expressed opinion in each meeting or cooperated with health officials in searching, analyzing, planning and doing the activities for solving the CCA problem or participated in establishing the health funds for opisthorchiasis prevention and control.

The result in Table 3 shows the adjusted odds ratio $(\mathrm{OR})$ and $95 \%$ confidence interval $(95 \% \mathrm{CI})$ from the multivariate analysis. Factors associated with the community participation for CCA prevention among rural residents near wetland areas in Ubon Ratchathani were age and the preventing behavior for CCA. There was a clear association with age: compared with the $\leq 44$ years, participants with aged 45-59 years had an increased association with the community participation for CCA prevention ( $\mathrm{OR}=1.99,95 \% \mathrm{CI}: 1.37-2.90)$, and this was higher still in those with aged $\geq 60$ years $(\mathrm{OR}=2.80$, 95\%CI: 1.77-4.41). Participants with secondary school education had also increased association with them $(\mathrm{OR}=1.58,95 \% \mathrm{CI}: 1.07-2.34)$. Similarly, participants with high level of preventing behavior had higher community participation for CCA prevention than those in low level about 2.57 times.

\section{Discussion}

This was a community-based cross-sectional analytic study aimed to investigate factors related to the community participation in CCA prevention among rural people residing around wetland areas in Ubon 
Table 3. Factors associated with Community Participation in Cholangiocarcinoma Prevention among Rural People Residing Near Wetland Areas in Ubon Ratchathani, Thailand

\begin{tabular}{|c|c|c|c|c|}
\hline Variables & $\mathrm{OR}^{*}$ & $\mathrm{OR}^{* *}$ & $95 \% \mathrm{CI}$ & p-value \\
\hline$\overline{\operatorname{Sex}}$ & & & & 0.924 \\
\hline Male & 1.00 & 1.00 & & \\
\hline Female & 1.14 & 0.98 & $0.72-1.35$ & \\
\hline Age (years) & & & & $<0.001$ \\
\hline$\leq 44$ & 1.00 & 1.00 & & \\
\hline $45-59$ & 1.97 & 1.99 & $1.37-2.90$ & \\
\hline$\geq 60$ & 2.70 & 2.80 & $1.77-4.41$ & \\
\hline Occupation & & & & 0.324 \\
\hline Farmer/Laborer & 1.00 & 1.00 & & \\
\hline Commercial/Trading & 0.37 & 0.48 & $0.23-1.01$ & \\
\hline Government officer & 0.54 & 0.81 & $0.36-1.83$ & \\
\hline Education level & & & & 0.051 \\
\hline Primary school & 1.00 & 1.00 & & \\
\hline Secondary school & 1.09 & 1.58 & $1.07-2.34$ & \\
\hline Bachelor degree or higher & 0.37 & 0.63 & $0.24-1.64$ & \\
\hline Marital status & & & & 0.533 \\
\hline Single & 1.00 & 1.00 & & \\
\hline Married & 1.57 & 1.44 & $0.86-2.37$ & \\
\hline Divorced & 1.60 & 0.99 & $0.49-2.02$ & \\
\hline Widowed & 0.97 & 0.92 & $0.36-2.33$ & \\
\hline \multicolumn{3}{|c|}{ Household income per year (Baht) } & & 1.000 \\
\hline$\leq 10,000$ & 1.00 & 1.00 & & \\
\hline $10,001-15,000$ & 1.10 & 1.14 & $0.72-1.80$ & \\
\hline$>15,000$ & 1.12 & 1.28 & $0.89-1.83$ & \\
\hline \multicolumn{3}{|c|}{ Knowledge on opisthorchiasis and CCA } & & 0.462 \\
\hline Low ( $\leq 7$ scores $)$ & 1.00 & 1.00 & & \\
\hline High (>7 scores) & 1.10 & 1.12 & $0.83-1.50$ & \\
\hline Perceived susceptibility & & & & 0.845 \\
\hline Low ( $\leq 11.72$ scores $)$ & 1.00 & 1.00 & & \\
\hline High (>11.72 scores) & 0.93 & 0.97 & $0.72-1.30$ & \\
\hline Perceived seriousness & & & & 0.10 \\
\hline Low $(\leq 11.93$ scores $)$ & 1.00 & 1.00 & & \\
\hline High ( $>11.93$ scores $)$ & 1.25 & 1.29 & $0.95-1.76$ & \\
\hline Perceived benefits & & & & 0.315 \\
\hline Low $(\leq 12.72$ scores $)$ & 1.00 & 1.00 & & \\
\hline High (>12.72 scores) & 1.28 & 1.18 & $0.85-1.63$ & \\
\hline Perceived barriers & & & & 0.150 \\
\hline Low & 1.00 & 1.00 & & \\
\hline High $(>12.13$ scores $)$ & 0.81 & 0.81 & $0.61-1.08$ & \\
\hline \multirow{2}{*}{\multicolumn{5}{|c|}{$\begin{array}{l}\text { Preventing behavior for CCA prevention and control }<0.001 \\
\text { Low }(\leq 22 \text { scores }) \\
1.00 \quad 1.00\end{array}$}} \\
\hline Low ( $\leq 22$ scores $)$ & & & & \\
\hline High (>22 scores) & 2.52 & 2.57 & $1.91-3.44$ & \\
\hline
\end{tabular}

*Crude odds ratio from univariate analysis; **Adjusted odds ratio for all other variables in the table

Ratchathani, Thailand. This topography is linked to the high prevalence of $O$. viverrini infection than other areas (Wattanayingcharoenchai et al., 2011). Although, a cross-sectional study can be very suggestive of possible associations, the limitations in establishing a temporal relationship between exposure and outcome may be concerned (Gordis, 2004). So, this topic could be conducting the relationship from other study designs in the future such as case-control study or cohort study.

The community participation for CCA prevention among the participants in this present study was regularly participated in preventing CCA according to the health official's advice. Conversely, there were some issues that the most participants had never participated; for examples, they had never participated with health officials in searching, analyzing, planning and doing the activities for solving the CCA problem. This finding may be a baseline data to set a program for improving the participation in the further studies. It might be taking some experiences from previous studies to set the program; for example, it is possible to take the fun activities and some initial external supports to improve the participation (Saranrittichai et al., 2012) or use of trained Village Health Volunteers to be alternative means for the transfer of health knowledge in areas where the numbers of health personnel are limited (Promthet et al., 2012).

The present study showed that factors significantly associated with the community participation for CCA prevention among rural people residing near wetland areas in Ubon Ratchathani were age and the preventing behavior for CCA. The middle-aged (45-59 years) and elder ( $\geq 60$ years) were associated with the community participation for CCA prevention. They were the main participants including the community leaders, Village Health Volunteers and housewives who cook for their families. These participants were a major key or answer to develop and empower the community participation for opisthorchiasis-linked CCA prevention in this area. This finding is similar to other studies as it used the community-based approach for opisthorchiasis prevention and control in Khon Kaen, Northeast Thailand (Wongba et al., 2011; Duangsong et al., 2013), and it is also similar to a participatory approach for prevention of cancer and noncommunicable diseases among middle-aged women in the Northeast of Thailand (Senarak et al., 2006). With respect to the preventing behavior for CCA, participants with high level of preventing behavior had higher community participation than those in low level. This has the same result compared to the behavior towards opisthorchiasis prevention through action research with increasing the behavior scores after the study (Wongba et al., 2011).

There were several methods for solving the problem on opisthorchiasis-linked CCA in Thailand from the past until now (Jongsuksuntigul and Imsomboon, 1998; Jongsuksuntigul and Imsomboon, 2003; Wongba et al., 2011; Duangsong et al., 2013) but the prevalence is still remaining today. Fortunately, today there is a good project on opisthorchiasis control that is integrated methodologies to get close to the goal. This project is called "Lawa model" which was proposed as a new strategy for controlling O. viverrini infection using the EcoHealth/One Health approach both in communities and schools (Sripa et al., 2015). Interestingly, some other parts of Thailand and neighboring Mekong countries are noticed to have followed this method. Furthermore, the present study site at Ubon Ratchathani may use this approach as a guide for opisthorchiasis-linked CCA prevention and control.

In conclusion, as we know that the factors associated with the community participation in CCA prevention in this present study were age and the preventing behavior for CCA. Both factors will be taken to operate the community participation approach for CCA prevention through the participatory action research (PAR) in the next study. 


\section{Acknowledgements}

This research was supported by the Thailand Research Fund and Ubon Ratchathani Rajabhat University (Research grant No. 2557A16402006).

\section{References}

Duangsong R, Promthet S, Thaewnongiew K (2013). Development of a community-based approach to opisthorchiasis control. Asian Pac J Cancer Prev, 14, 7039-43.

Gordis L (2004). Epidemiology. 3rd ed. Philadelphia, Elsevier Saunders.

Grundy-Warr C, Andrews RH, Sithithaworn P, et al (2012). Raw attitudes, wetland cultures, life-styles: Socio-cultural dynamics relating to Opisthorchis viverrini in the Mekong basin. Parasitology Int, 61, 65-70.

Jongsuksuntigul P, Imsomboon T (1998). Epidemiology of opisthorchiasis and national control program in Thailand. Southeast Asian J Trop Med Public Health, 29, 327-32.

Jongsuksuntigul P, Imsomboon T (2003). Opisthorchiasis control in Thailand. Acta Trop, 88, 229-32.

Kamsa-ard S, Wiangnon S, Suwanrungruang K, et al (2011). Trends in liver cancer incidence between 1985 and 2009, Khon Kaen, Thailand: cholangiocarcinoma. Asian Pac J Cancer Prev, 12, 2209-13.

Khuhaprema T, Attasara P, Sriplung H, Wiangnon S, Sangrajrang S (2013). Cancer in Thailand, Vol. VII, 2007-2009. Bangkok, Bangkok Medical Publisher.

Manwong M, Songserm N, Promthet S, Matsuo K (2013). Risk factors for cholangiocarcinoma in the lower part of Northeast Thailand: a hospital-based case-control study. Asian Pac J Cancer Prev, 14, 5953-6.

Parkin DM, Srivatanakul P, Khlat M, et al (1991). Liver cancer in Thailand. I. A case-control study of cholangiocarcinoma. Int J Cancer, 48, 323-8.

Parkin DM, Ohshima H, Srivatanakul P, Vatanasapt V (1993). Cholangiocarcinoma: epidemiology, mechanisms of carcinogenesis and prevention. Cancer Epidemiol Biomarkers Prev, 2, 537-44.

Promthet S, Wiangnon S, Senarak W, et al (2012). Evaluation of health education in the multi-professional intervention and training for ongoing volunteer-based community health programme in the north-east of Thailand. Asian Pac J Cancer Prev, 13, 1753-5.

Saranrittichai K, Senarak W, Promthet S, et al (2012). Health behavior after multiprofessional intervention and training for ongoing volunteer-based community health programme intervention in the North-East of Thailand: what changed and what not? Asian Pac J Cancer Prev, 13, 4801-5.

Senarak W, Chirawatkul S, Markovic M (2006). Health promotion for middle-aged Isan women, Thailand: a participatory approach. Asian Pac J Cancer Prev, 7, 55-9.

Sithithaworn P, Andrews RH, Van De N, et al (2012). The current status of opisthorchiasis and clonorchiasis in the Mekong Basin. Parasitology Int, 61, 10-6.

Songserm N, Promthet S, Sithithaworn P, et al (2012). Risk factors for cholangiocarcinoma in high-risk area of Thailand: Role of lifestyle, diet and methylenetetrahydrofolate reductase polymorphisms. Cancer Epidemiol, 36, 89-94.

Sriamporn S, Pisani P, Pipitgool V, et al (2004). Prevalence of Opisthorchis viverrini infection and incidence of cholangiocarcinoma in Khon Kaen, Northeast Thailand. Trop Med Int Health, 9, 588-94.

Sripa B, Kaewkes S, Sithithaworn P, et al (2007). Liver fluke induces cholangiocarcinoma. PLoS Med, 4, 201.

Sripa B, Tangkawattana S, Laha T, et al (2015). Toward integrated opisthorchiasis control in northeast Thailand: the Lawa project. Acta Trop, 141, 361-7.

Thaewnongiew K, Singthong S, Kutchamart S, et al (2014). Prevalence and risk factors for Opisthorchis viverrini infections in Upper Northeast Thailand. Asian Pac J Cancer Prev, 15, 6609-12.

Vatanasapt V, Uttaravichien T, Mairiang E, et al (1990). Cholangiocarcinoma in north-east Thailand. Lancet, 335, 116-7.

Wattanayingcharoenchai S, Nithikathkul C, Wonsaroj T, Royal L, Reungsang P (2011). Geographic information system of Opisthorchis viverrini in northeast Thailand. Asian Biomedicine, 5, 687-91.

Wongba N, Thaewnongiew K, Phathee K, et al (2011). Liver fluke prevention and control in the Northeast of Thailand through action research. Asian Pac J Cancer Prev, 12, 1367-70. 